OPEN ACCESS

Edited by:

Thorsten Roland Doeppner, University Medical Center Göttingen,

Germany

Reviewed by:

Melissa R. Andrews,

University of Southampton,

United Kingdom

Warren J. Alilain,

University of Kentucky, United States

*Correspondence: William Rodemer rodemer@temple.edu Michael E. Selzer mselzer@temple.edu

Received: 15 November 2019 Accepted: 02 March 2020

Published: 19 March 2020

Citation:

Rodemer W, Zhang G, Sinitsa I, Hu J, Jin L, Li S and Selzer ME (2020) PTP $\sigma$ Knockdown in Lampreys Impairs Reticulospinal Axon Regeneration and Neuronal Survival After Spinal Cord Injury.

Front. Cell. Neurosci. 14:61. doi: 10.3389/fncel.2020.00061

\section{PTPo Knockdown in Lampreys Impairs Reticulospinal Axon Regeneration and Neuronal Survival After Spinal Cord Injury}

\author{
William Rodemer ${ }^{1 *}$, Guixin Zhang ${ }^{1}$, Isabelle Sinitsa ${ }^{1,2}$, Jianli Hu ${ }^{1}$, Li-qing Jin ${ }^{1}$, Shuxin $\mathrm{Li}^{1,3}$ \\ and Michael E. Selzer ${ }^{1,4 *}$
}

'Shriners Hospitals Pediatric Research Center, Lewis Katz School of Medicine, Temple University, Philadelphia, PA, United States, ${ }^{2}$ College of Science and Technology, Temple University, Philadelphia, PA, United States, ${ }^{3}$ Department of Anatomy and Cell Biology, Lewis Katz School of Medicine, Temple University, Philadelphia, PA, United States, ${ }^{4}$ Department of Neurology, Lewis Katz School of Medicine, Temple University, Philadelphia, PA, United States

Traumatic spinal cord injury (SCl) results in persistent functional deficits due to the lack of axon regeneration within the mammalian CNS. After SCl, chondroitin sulfate proteoglycans (CSPGs) inhibit axon regrowth via putative interactions with the LAR-family protein tyrosine phosphatases, PTPo and LAR, localized on the injured axon tips. Unlike mammals, the sea lamprey, Petromyzon marinus, robustly recovers locomotion after complete spinal cord transection (TX). Behavioral recovery is accompanied by heterogeneous yet predictable anatomical regeneration of the lamprey's reticulospinal (RS) system. The identified RS neurons can be categorized as "good" or "bad" regenerators based on the likelihood that their axons will regenerate. Those neurons that fail to regenerate their axons undergo a delayed form of caspase-mediated cell death. Previously, this lab reported that lamprey PTPo mRNA is selectively expressed in "bad regenerator" RS neurons, preceding SCl-induced caspase activation. Consequently, we hypothesized that PTP $\sigma$ deletion would reduce retrograde cell death and promote axon regeneration. Using antisense morpholino oligomers (MOs), we knocked down PTP $\sigma$ expression after TX and assessed the effects on axon regeneration, caspase activation, intracellular signaling, and behavioral recovery. Unexpectedly, PTPo knockdown significantly impaired RS axon regeneration at 10 weeks post-TX, primarily due to reduced long-term neuron survival. Interestingly, cell loss was not preceded by an increase in caspase or p53 activation. Behavioral recovery was largely unaffected, although PTP $\sigma$ knockdowns showed mild deficits in the recovery of swimming distance and latency to immobility during open field swim assays. Although the mechanism underlying the cell death following TX and PTPo knockdown remains unknown, this study suggests that PTP $\sigma$ is not a net negative regulator of long tract axon regeneration in lampreys.

Keywords: spinal cord injury, CPSGS, PTPRS, lampreys, cell death, regeneration 


\section{INTRODUCTION}

Spinal cord injury (SCI) results in persistent functional deficits in mammals because injured CNS axons fail to regenerate. This failure results from both inhibitory factors in the extracellular environment and intrinsic limitations to regenerative capacity (Tran et al., 2018). Among the most potent and well-described environmental factors are the chondroitin sulfate proteoglycans (CSPGs), which are abundantly expressed around CNS lesion as a key component of the glial scar (Stichel et al., 1999). Digesting CSPGs with chondroitinase increases axon outgrowth on a CSPG substrate in vitro, promotes sprouting of spared fibers in vivo and enhances functional recovery from SCI in animal models (Zuo et al., 1998; Bradbury et al., 2002; Barritt et al., 2006; Houle et al., 2006).

The LAR-family of receptor-type protein tyrosine phosphatases (RPTPs), including LAR and PTP $\sigma$, have been identified as putative CSPG receptors in mammals (Shen et al., 2009; Fisher et al., 2011). Consisting of approximately $1.9 \times 10^{3}$ amino acids for their longest splice variants, these transmembrane receptors are structurally highly similar (Chagnon et al., 2004). Starting from the extracellular $\mathrm{N}$-terminal, they contain three Ig-like domains, the first of which interacts with CSPGs via conserved lysine residues. These domains are followed by a number of fibronectin type III (FNIII) repeats, which vary depending on splicing. Intracellularly, there are two phosphatase domains, D1 and D2. D1 is generally believed to be active while D2 is considered structurally inactive and may serve in a more regulatory role. Genetic deletion or peptide inhibition of LAR and PTP $\sigma$ has been reported to enhance CNS axon regeneration after SCI, likely via RhoA-dependent mechanisms (Shen et al., 2009; Fisher et al., 2011; Lang et al., 2015; Ohtake et al., 2016). Notably, LAR and PTP $\sigma$ often colocalize within the same neuronal populations. In mammalian studies, targeting LAR or PTP $\sigma$ in isolation was sufficient to elicit pro-regenerative functional effects, but inhibiting both receptors simultaneously additively enhanced axon outgrowth in vitro (Ohtake et al., 2016).

Nevertheless, the role of LAR-family RPTPs in long tract regeneration remains unclear. Although, PTP $\sigma$ knockdown has been reported to enhance corticospinal tract axon regeneration, the use of partial injury models and the complexity of the mammalian CNS make it difficult to distinguish true regeneration from compensatory sprouting of spared fibers (Fry et al., 2010). Moreover, the effects of receptor inhibition on axon regeneration appear to be context-dependent. Following sciatic nerve crush, an early report found PTP $\sigma$ deletion enhanced sensory axon regeneration but increased pathfinding errors (McLean et al., 2002). However, other studies using sciatic nerve injury models reported that deletion of LAR or PTP $\delta$, a third LAR-family RPTP member, reduced sensory axon regeneration and worsened outcomes (Xie et al., 2001; Van der Zee et al., 2003). As a further complication, RPTPs have been reported to modulate the immune responses to CNS injury, as well as the survival and differentiation of local oligodendrocyte precursors and neural progenitors (Dyck et al., 2015, 2018, 2019; Ohtake et al., 2017).
Unlike mammals, sea lampreys (Petromyzon marinus) recover robustly from complete spinal cord transection (TX) despite the presence of a CSPG-rich scar that forms around the TX site. In lampreys, peak CSPG expression occurs approximately 2 weeks after TX and then slowly returns to normal levels by 10 weeks post-TX (Lurie et al., 1994; Zhang et al., 2014). Behavioral recovery is accompanied by true regeneration of reticulospinal (RS) axons, which facilitate descending control of locomotion. The RS system comprises approximately 2,000 neurons in total that are distributed within the hindbrain and posterior aspect of the midbrain. Of these, there are 18 pairs of large identified neurons, which project to at least the level of the cloaca. Following complete TX, all descending connections are severed. However, after a period of retraction, RS axons begin to regenerate, reaching the TX scar by approximately 3 weeks (Yin and Selzer, 1983). This regeneration is heterogeneous but predictable. Approximately half of the identified neurons will reliably regenerate to at least $5 \mathrm{~mm}$ beyond the TX, while the other half fail to regenerate and undergo a severely delayed form of apoptosis that peaks between 12 and 16 weeks post-TX (Shifman et al., 2008). As the regeneration probability for each identified neuron is broadly stable across studies, they can be semi-permanently classified as "good" or "bad" regenerators (Table 1). However, the exact definitions can vary depending on the study. In this report, neurons with regeneration probabilities $>50 \%$ were considered "good" regenerators.

Recently, this lab reported that the CSPG-receptor, PTP $\sigma$, is expressed preferentially in bad regenerators, both before and after TX (Zhang et al., 2014). Consequently, we hypothesized that knocking down PTP $\sigma$ with antisense morpholino oligomers (MOs) would promote regeneration and reduce retrograde neuronal death after TX.

\section{MATERIALS AND METHODS}

\section{Animals and Surgery}

Wild-caught larval sea lampreys, approximately $8-12 \mathrm{~cm}$ in length (3-5 years old), obtained from the streams of Lake Michigan were maintained in freshwater tanks at room temperature until use. All animal procedures described in this report were performed with approval from Temple University's Institutional Animal Care and Use Committee. The total number of animals used is summarized in Table 2.

Lampreys were anesthetized by immersion in $0.1 \%$ tricaine methanesulfonate (MS-222, Western Chemical Inc., Washington, DC, USA) in Ringer's solution and the spinal cords were exposed by a small longitudinal incision along the dorsal midline in the gill region. Spinal cords were completely transected with Castroviejo scissors at the level of the 5th gill. The completeness of the TX was confirmed by visual inspection of the severed spinal cord stumps. To retrogradely transfect RS neurons, a small gel foam pledget soaked with $1 \mu \mathrm{l}$ of $1 \mathrm{mM}$ fluorescein-tagged MOs was gently inserted on top of the severed spinal cord immediately after the injury. RS neurons that were successfully transfected could then be identified by their fluorescent labeling. Afterward, the animals were allowed 
TABLE 1 | Regeneration probabilities for the identified reticulospinal (RS) neurons.

\begin{tabular}{|c|c|c|c|c|c|c|c|c|c|c|}
\hline \multirow[b]{2}{*}{ Neuron } & \multicolumn{10}{|c|}{ Good regenerators ( > 50\% Regen. Probability) } \\
\hline & 16 & 14 & B6 & M4 & Mth' & 15 & 13 & B5 & & \\
\hline \multirow[t]{2}{*}{ Regen. Prob. (\%) } & 57 & 59 & 61 & 63 & 69 & 69 & 70 & 70 & & \\
\hline & \multicolumn{10}{|c|}{ Bad regenerators (<50\% Regen. Probability) } \\
\hline Neuron & 11 & B3 & Mth & B4 & M2 & M3 & B1 & 12 & B2 & M1 \\
\hline Regen. Prob. (\%) & 4 & 6 & 7 & 11 & 13 & 13 & 19 & 37 & 46 & 48 \\
\hline
\end{tabular}

TABLE 2 | Summary of animal experiments.

\begin{tabular}{|c|c|c|c|c|c|c|c|c|c|c|c|c|c|c|}
\hline \multirow[t]{3}{*}{ Experiment } & \multicolumn{14}{|c|}{ Sample size $(N)$} \\
\hline & \multirow[t]{2}{*}{ MO } & \multicolumn{13}{|c|}{ Weeks post-TX } \\
\hline & & -1 & 1 & 2 & 3 & 4 & 5 & 6 & 7 & 8 & 9 & 10 & 20 & 24 \\
\hline \multirow[t]{2}{*}{ MO efficiency } & Ctrl & . & . & . & . & $9^{a}$ & . & . & . & . & . & . & . & 3 \\
\hline & РТР $\sigma$ & . & . & . & . & $8^{a}$ & . & . & . & . & . & . & . & 2 \\
\hline \multirow[t]{2}{*}{ In situ hybridization } & Ctrl & . & . & 7 & . & . & . & . & . & . & . & . & . & . \\
\hline & РТРо & . & . & 8 & . & . & . & . & . & . & . & . & . & . \\
\hline \multirow[t]{2}{*}{ RS axon regeneration } & Ctrl & . & . & . & . & . & . & . & . & . & . & 9 & . & . \\
\hline & РТР & . & . & . & . & . & . & . & . & . & . & 11 & . & . \\
\hline \multirow[t]{2}{*}{ FLICA } & Ctrl & . & . & 5 & . & 9 & . & . & 6 & . & . & 6 & 6 & . \\
\hline & РТР $\sigma$ & . & . & 6 & . & 8 & . & . & 6 & . & . & 6 & 6 & . \\
\hline \multirow[t]{3}{*}{ Swimming behavior assay ${ }^{\mathrm{b}}$} & Naïve & 58 & . & . & . & . & . & . & . & . & . & . & . & . \\
\hline & Ctrl & . & 17 & 17 & 5 & 15 & 15 & 15 & 15 & 15 & 15 & 10 & . & . \\
\hline & РТР & . & 17 & 17 & 5 & 15 & 15 & 15 & 15 & 14 & 14 & 8 & . & . \\
\hline \multirow[t]{2}{*}{ Western blot, brain } & Ctrl & . & . & 4 & . & . & . & . & . & . & . & . & . & . \\
\hline & РТР & . & . & 4 & . & . & . & . & . & . & . & . & . & . \\
\hline \multirow[t]{2}{*}{ Western blot, spinal cord } & Ctrl & . & . & 5 & . & . & . & . & . & . & . & . & . & . \\
\hline & PTP $\sigma$ & . & . & 4 & . & . & . & . & . & . & . & . & . & . \\
\hline \multirow[t]{2}{*}{ Immunofluorescence/Histochemistry } & Ctrl & . & . & 4 & . & . & . & . & . & . & . & . & . & . \\
\hline & РТР $\sigma$ & . & . & 3 & . & . & . & . & . & . & . & . & . & . \\
\hline
\end{tabular}

${ }^{a}$ Transfection efficiency was assessed using the FLICA 4 week post-TX cohort. ${ }^{b}$ Animal sample size represents animals followed longitudinally before the injury and from 4 to 10 weeks or 1 to 10 weeks post-TX.

to recover on ice for $2 \mathrm{~h}$; then the gel foam was removed and the animals placed in cold water tanks overnight. The following day, animals were returned to room temperature tanks until needed.

To evaluate true axon regeneration beyond the lesion, some lampreys received a second complete TX, $5 \mathrm{~mm}$ caudal to the first, at 10 weeks post-(1st) transfection. Regenerated RS neurons were retrogradely labeled by applying a gel foam pledget soaked in $1 \mu \mathrm{l}$ of a solution of $5 \%$ dextran tetramethylrhodamine (DTMR, 10,000 MW; Em. 550 nm, Ex. $580 \mathrm{~nm}$; Invitrogen, D1817) in Tris- $\mathrm{HCl}$ buffer ( $\mathrm{pH} 7.4)$ to the lesion. Animals were euthanized 1 week later by immersion in saturated benzocaine and brains were dissected, fixed in $4 \%$ paraformaldehyde, and imaged under widefield fluorescent (Nikon 80i, $4 \times$ objective) or confocal (Nikon C2, 10× objective) microscopy. Morphant identified neurons were assessed individually based on position and morphology. A neuron was counted as "regenerated" if the cell was double positive for fluorescein-conjugated MO and dextran dye. Statistical analysis was performed with GraphPad Prism 8 using a two-tailed student's $t$-test.

To assess TX-induced caspase activation, lampreys were euthanized at 2, 4, 7, 10, or 20 weeks post-TX and processed for fluorochrome-labeled inhibitors of caspase activation (FLICA) as previously described (Barreiro-Iglesias and Shifman, 2012; Hu et al., 2013). Briefly, freshly dissected brains were immersed in sulforhodamine poly caspase FLICA reagent (SR-VAD-FMK;
Ex. 570 nm, Em. 590 nm; Image-IT Live Red Poly Caspases Detection Kit, Cat I305101, Thermo Fisher Scientific, Waltham, MA, USA), which irreversibly binds activated caspases $1,3,4,5$, $6,7,8$, and 9 , then thoroughly washed, flat-mounted and fixed with $4 \%$ paraformaldehyde. Brains were imaged by wide-field fluorescence microscopy (Nikon $80 \mathrm{i}, 4 \times$ objective). Morphantand FLICA-positive identified neurons were counted, and the results were analyzed with GraphPad Prism 8 using one-way ANOVA with Sidak post hoc multiple comparisons tests.

\section{Antisense Morpholino Oligomers}

Lamprey LAR-family RPTPs are not annotated in the lamprey reference genome (P.marinus_7.0). However, by aligning PTP $\sigma$ DNA sequences from mammals to lampreys using basic local alignment search tools (BLAST), genome regions encoding PTP $\sigma$ were identified and partially cloned from cDNA (Zhang et al., 2014). Introns were identified by comparing genomic sequences with the cDNA exonic sequence. Using Gene Tools LLC custom oligomer design service, we designed a splice acceptor and splice donor pair of MOs complementary to the exon-intron junctions flanking an exon encoding a region near the 3rd Ig-like domain of lamprey PTPб (MOРTPб; GL479748:15741-15933; splice acceptor MO sequence, 5' $5^{\prime}$ AGA GCC TGC GGC AAG TCA GGC AGA A-3'; splice donor MO sequence, 5' -CTG CTG CTG CGT ATC CTC ACC CTT C-3'). For optimal efficiency, a 1:1 suspension of splice acceptor and splice donor oligomers 
were used for all experiments (approximately $0.5 \mathrm{mM}$ each suspended in water). The Gene Tools LLC Standard Control MO $\left(\mathrm{MO}_{\mathrm{Ctrl}}\right)$ was selected for the negative control (MO sequence, 5'-CCT CTT ACC TCA GTT ACA ATT TAT A-3'). This MO targets a rare mutation at position 705 in human beta-globin pre-mRNA and is recommended by Gene Tools LLC for having minimal biological activity. All MOs used in this study were covalently bound at the $3^{\prime}$ end to fluorescein (Ex $501.5 \mathrm{~nm}, \mathrm{Em}$ $524.5 \mathrm{~nm})$.

\section{Open Field Behavioral Assay}

Naïve and TX'd lamprey locomotion was assessed 3 days per week, beginning 1 week before injury until 10 weeks post-injury. Individual animals were gently placed in a Nalgene pan shallowly filled with aquarium water and monitored by an overhead camera for 2 min of free swim. Swimming quality was assessed on a semiquantitative "movement" score: (0) no movement below lesion; (1) spastic movements below lesion; (2) brief forward movements; (3) persistent abnormal swimming, $<80 \%$ of time with dorsal side up; (4) persistent abnormal swimming, $>80 \%$ of time dorsal side up; and (5) normal swimming, 100\% of time dorsal side up. Videos were processed with ANY-maze animal tracking software (Stoelting) to quantify swimming parameters including total distance traveled, maximum swimming speed, time spent mobile, and latency to immobility. Statistical analysis of weekly averages was performed with Graphpad Prism 8 using two-way ANOVA with a post hoc Sidak multiple comparisons test.

\section{Western Blot}

To determine protein expression levels, freshly dissected lamprey brains or spinal cords (from the 2nd gill to $5 \mathrm{~mm}$ distal to the TX) were snap-frozen in liquid nitrogen and stored at $-80^{\circ} \mathrm{C}$ until use. Frozen lamprey specimens were thawed on ice and suspended in cold lysis buffer (CelLytic MT; Sigma-Aldrich, St. Louis, MO, USA, Cat C3228) supplemented with a cocktail of protease and phosphatase inhibitors (Halt Protease and Phosphatase Inhibitor Cocktail 100×, Thermo Fisher Scientific, Waltham, MA, USA) and homogenized by sonication. Supernatants were collected following brief centrifugation to remove debris and protein concentration was assessed by Bradford Assay (Bio-Rad, Cat 500-0006). The samples, containing $25 \mu \mathrm{g}$ of protein supplemented with reducing reagent (Invitrogen, Cat NP0004) and loading buffer (Invitrogen, NP0007), were denatured by heating at $75^{\circ} \mathrm{C}$. Denatured samples were loaded into a $4-12 \%$ NuPage Bis-Tris mini-gel (Invitrogen, Cat NP0321BOX), separated by electrophoresis, then wet-transferred onto a PVDF membrane.

After transfer, PVDF membranes were washed thoroughly with TBS, blocked with 5\% non-fat milk, and incubated with primary antibody diluted in $1 \%$ non-fat milk overnight at $4^{\circ} \mathrm{C}$. The following day, membranes were washed thoroughly with TBS, and incubated with near-IR secondary antibodies in PBS Blocking Buffer (Li-Cor, Cat 927-40000) with 0.1\% Tween-20 and $0.01 \%$ SDS final concentrations. Membranes were imaged with an Odyssey CLx Imaging System (Li-Cor). To assess additional proteins, the immunoblotting procedure was sequentially repeated.

Signal intensity was measured and blots were processed for presentation using Image Studio Lite (version 4.0, LiCor). Statistical analysis was performed on signal intensity values with GraphPad Prism 8 using two-tailed student's $t$ tests. Primary antibodies used in this study include: rabbit antiphospho-Akt mAB (T308; 1:1,000; Cell Signaling Technology, Danvers, MA, USA, Cat 2965; RRID:AB_2255933), rabbit antipan-Akt mAB (1:3,000; Cell Signaling Technology, Danvers, MA, USA, Cat 4691; RRID:AB_915783), rabbit anti-p53 (1:1,000; AbClonal, Cat A5761; RRID:AB_2766515) and mouse anti-Actin mAB (1:10,000; Millipore, Kankakee, IL, USA, Cat 1501; RRID:AB_2223041). Primary antibodies were detected with IRDye 680 or IRDye 800 secondary antibodies (1:20,000, Li-Cor).

\section{Immunofluorescence}

Flat-mounted, PFA fixed, lamprey brains were dehydrated, embedded in paraffin, horizontally sectioned on a microtome (10 $\mu \mathrm{m}$ section thickness), and mounted on ColorFrost Plus slides. The samples were then processed for immunofluorescence as follows: rehydrated to PBS; incubated with Citrate Buffer $(\mathrm{pH}$ 6.0) for antigen retrieval (20 min boiling then $20 \mathrm{~min}$ RT); blocked with PBS with $0.1 \%$ bovine serum albumin and $0.2 \%$ Triton $\mathrm{X}-100$ for $1 \mathrm{~h}$ RT; incubated with rabbit anti-p53 primary antibody diluted in blocking buffer overnight at $4^{\circ} \mathrm{C}$ (1:200; AbClonal, Cat A5761; RRID:AB_2766515); incubated with anti-rabbit AlexFluor+ 594 secondary antibody for $1 \mathrm{~h}$ RT in the dark (1:400; Invitrogen, Cat A32740; RRID:AB_2762824); and mounted under glass coverslips with Fluoromount-G (Southern Biotech, Birmingham, AL, USA). The samples were thoroughly washed with PBS between each step. Fluorescence images were captured via confocal microscopy (Nikon C2 microscope, 10× objective) and processed with NIS-Elements and Adobe Photoshop.

\section{Microglia Staining}

To assess the effects of PTP $\sigma$ knockdown on the local immune response to SCI, at 2 weeks pTX, microglia were stained by isolectin B4 -HRP (1:200; Sigma-Aldrich, St. Louis, MO, USA, Cat\# L5391) and DAB histochemistry was performed on $10 \mu \mathrm{m}$ horizontal sections (i.e., cut parallel to the dorsal surface) of fixed, paraffin-embedded lamprey spinal cord. For each spinal cord, the number of labeled microglia were recorded from each of four serial sections proximal to the injury, near the median plane. Macrophages or microglia residing within the central canal were excluded. The region assessed included the TX site and extended $600 \mu \mathrm{m}$ Rostralward. Statistical analysis was performed on the mean number of microglia observed per horizontal section (for $\mathrm{MO}, n=2$ animals $\times 4$ sections $=8$; for $\mathrm{MO}_{\mathrm{Ctrl}}$, $n=3$ animals $\times 4$ sections $=12$ ) using a two-tailed student's $t$-test.

\section{In situ Hybridization}

Free-floating, fixed wholemount lamprey brains were imaged by widefield fluorescence microscopy (Nikon 80i), then processed for ISH with a custom lamprey PTP $\sigma$ RNA probe as previously described (Swain et al., 1994; Zhang et al., 2014). Briefly, 
brains were washed with PBS containing 0.1\% Tween-20 and processed as follows: (1) immersed in hybridization solution (50\% Formamide, $5 \times$ SSC, $100 \mu \mathrm{g} / \mu \mathrm{l}$ Torula-Yeast RNA, $100 \mu \mathrm{g} / \mu \mathrm{l}$ Wheat germ tRNA, $50 \mu \mathrm{g} / \mu \mathrm{l}$ Heparin, $0.1 \%$ Tween20; $1 \mathrm{~h}$ at $50-55^{\circ} \mathrm{C}$ ); (2) incubated with biotinylated PTP $\sigma$ riboprobe $(1.5 \mu \mathrm{g} / \mathrm{ml})$ in hybridization solution (overnight at $\left.50-55^{\circ} \mathrm{C}\right)$; (3) washed with hybridization solution $(4 \times$ for $30 \mathrm{~min}$ at $\left.50-55^{\circ} \mathrm{C}\right)$; (4) washed with a $1: 1$ mix of hybridization solution and PBS with $0.1 \%$ Tween-20 $\left(2 \times\right.$ for $15 \mathrm{~min}$ at $\left.50-55^{\circ} \mathrm{C}\right)$; (5) washed with PBS containing $0.1 \%$ Tween-20 ( $2 \times$ for $30 \mathrm{~min})$; (6) incubated in blocking solution (PBS containing $0.1 \%$ BSA Fraction V and $0.2 \%$ Triton X-100; $4 \times$ for $30 \mathrm{~min}$ ); (7) incubated with streptavidin-AP (1:1000; Roche, Cat 11093266910) in blocking solution (overnight at $4^{\circ} \mathrm{C}$ ); (8) washed with blocking solution ( $4 \times$ for $30 \mathrm{~min})$; (9) washed with SMT buffer $(100 \mathrm{mM}$ $\mathrm{NaCl}, 50 \mathrm{mM} \mathrm{MgCl} 2,100 \mathrm{mM}$ Tris $\mathrm{pH}$ 9.5, 0.1\% Tween20; $4 \times$ for $30 \mathrm{~min}$ ); (10) incubated with ice-cold chromogen (NBT/BCIP, Roche, Cat 11681451001; $10 \mathrm{~min}$ ) in SMT buffer; (11) washed with PBS ( $3 \times$ for $5 \mathrm{~min}$ ); and (12) mounted on glass slides with $\mathrm{PBS}$ and imaged under reflected light stereomicroscopy.

Fluorescent and brightfield images were superimposed in Adobe Photoshop. Since, the images were taken under different conditions, cells did not perfectly overlap but could still be identified from position and morphology. Single and doublelabeled cells were counted and the resulting values were analyzed statistically with GraphPad Prism 8. To provide a complete overview of PTP $\sigma$ expression after TX with $\mathrm{MO}_{\mathrm{Ctrl}}$ or $\mathrm{MO}_{\mathrm{PTP} \sigma}$ treatment, a contingency analysis on all counted cells was performed using Fisher's exact test $\left[\alpha=0.05\right.$; categories: $\mathrm{MO}_{\mathrm{PTP} \sigma}$-treated, $\mathrm{PTP} \sigma(+)$; $\mathrm{MO}_{\mathrm{PTP}}{ }^{-}$ treated, $\mathrm{PTP} \sigma(-)$; $\mathrm{MO}_{\mathrm{Ctrl}}$-treated, $\mathrm{PTP} \sigma(+)$; and $\mathrm{MO}_{\mathrm{Ctrl}}$-treated, $\operatorname{PTP} \sigma(-)]$. As a complementary analysis, the mean number of PTP $\sigma$ positive neurons per lamprey with $\mathrm{MO}_{\mathrm{Ctrl}}$ or MOРTP treatment was assessed with a two-tailed student's $t$-test.

\section{RESULTS}

\section{MOs Reduced PTP $\sigma$ Expression Among RS Neurons}

Antisense MOs, which bind complementary target RNA via Watson-Crick base paring, have proven to be reliable vectors for inducing protein knockdown in lampreys (Zhang et al., 2015; Hu et al., 2017; Sobrido-Cameán et al., 2019). Importantly, MOs applied to the spinal cord stumps after TX are readily taken up by severed axons and retrogradely transported to their cell bodies in the brain (Zhang et al., 2015). MOs targeting lamprey PTP $(\mathrm{MO})$ were designed to interact with intron-exon junctions flanking an exon encoding a region in the 3rd Ig-like domain towards the N-terminal. This was predicted to induce an exon skipping event to reveal a premature stop codon, at which point the transcript would be degraded via nonsense-mediated decay mechanisms.

Although the half-life of PTP $\sigma$ in lampreys is unknown, the half-life of human PTP $\sigma$ is estimated to be between $16 \mathrm{~h}$ and 2 days (Cohen et al., 2013; Xiao and $\mathrm{Wu}, 2017$ ). Thus, PTP $\sigma$ must be continually synthesized to maintain expression levels. Previous studies demonstrated that MOs applied to the cut ends of lamprey RS axons immediately after TX reach their perikarya in the brain within 1 week of injury and are effective in reducing protein expression of their target RNAs (Zhang et al., 2015; Hu et al., 2017). After an initial 10-day period of retraction, axons of the identified RS neurons begin to regenerate, reaching the edge of the CSPG-rich scar by 3 weeks post-TX (Yin and Selzer, 1983). Therefore, it is likely that inhibiting the translation of PTP $\sigma$ will reduce its protein expression in axon tips at time points relevant to regeneration (Lurie et al., 1994).

To analyze PTP $\sigma$ mRNA expression at the level of individual RS neurons, 2 weeks after TX, we performed in situ hybridization in wholemount lamprey brains, using biotinylated riboprobes designed to hybridize to the fibronectin-III domain of lamprey PTPo (Figure 1). This region was chosen for specificity because it has low homology to the closely related LAR-family RPTPs, LAR and PTP $\delta$ (Zhang et al., 2014). Contingency analysis with Fisher's exact test, using the total counts of identified neurons,

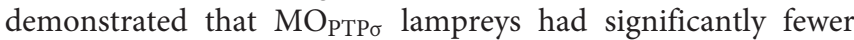
PTP $\sigma$ positive RS neurons compared to $\left.\mathrm{MO}_{\mathrm{Ctrl}}{ }^{* * *} p=0.0006\right)$. Reductions in PTP $\sigma$ expression were most evident among "bad regenerator" identified RS neurons, where PTP $\sigma$ is most highly expressed. $\mathrm{MO}_{\mathrm{PTP} \sigma}$ reduced the number of $\mathrm{PTP} \sigma$-expressing "bad regenerator" RS neurons per lamprey by approximately $43 \%\left({ }^{*} p=0.03\right)$. Non-significant reductions in PTP $\sigma$ were observed among "good regenerator" identified RS neurons (25\% reduction, $p=0.25$ ). Although knockdown was not complete, these results demonstrated that MO reduced PTP $\sigma$ expression as designed.

\section{PTPo Knockdown Impaired Axon Regeneration}

To assess axon regeneration following TX and PTP $\sigma$ knockdown, we utilized a double-labeling strategy. Ten weeks after the initial TX, a second TX was made $5 \mathrm{~mm}$ caudal to the first and a fluorescent dextran tracer was applied to retrogradely label neurons with regenerated axons (Figure 2). Using this approach, unexpectedly, we observed significantly fewer regenerated identified RS neurons per lamprey following PTP $\sigma$ knockdown relative to controls ( $\sim 29 \%$ fewer regenerated neurons, ${ }^{* *} p<0.01$; Figure $2 \mathrm{C}$ ). Interestingly, this impaired regeneration appeared to be largely due to reduced long-term neuron survival beginning around 10 weeks post-injury and worsening over time. By 20 weeks post-TX, 35\% fewer identified RS neurons survived following PTP $\sigma$ knockdown relative to controls $\left({ }^{* * *} p<0.001\right.$; Figure 4B).

In these studies, cell survival was assessed using labeling by fluorescently-tagged MOs. By design, MOs are persistent and extremely resistant to degradation by endonucleases. At 1 month post-TX, both control and PTP $\sigma$ MOs transfected the identified RS neurons with comparable efficiency (Figure 3). To confirm whether MO labeling persisted over long time periods, a small cohort of lampreys administered $\mathrm{MO}_{\mathrm{PTP} \sigma}$ or $\mathrm{MO}_{\mathrm{Ctrl}}$ were subjected to a second TX, 6 months after the first, and back labeled with DTMR. Importantly, this TX was made rostral to the first, at the level of the third gill, 

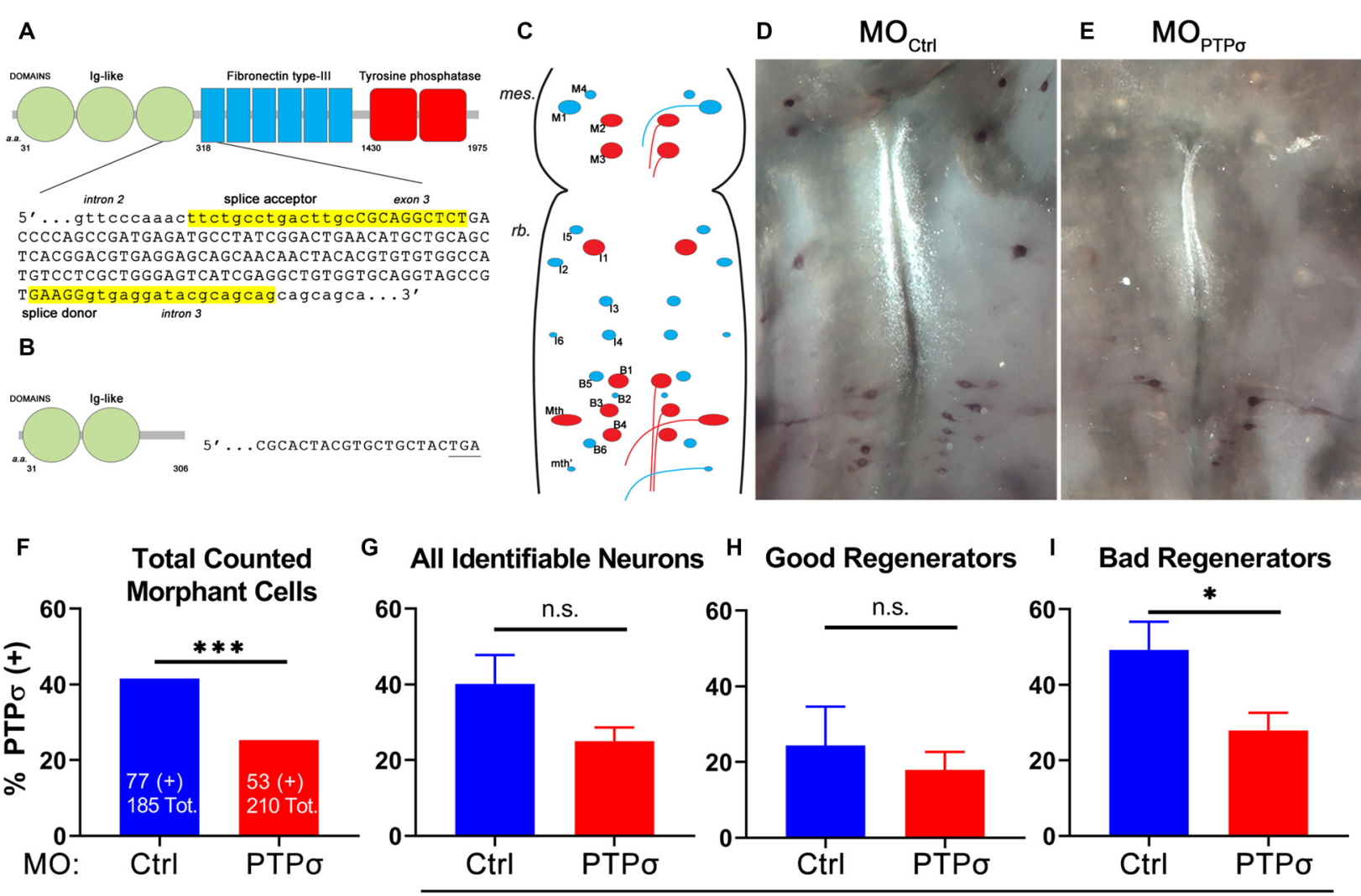

Mean Per Lamprey

FIGURE 1 | Splice-blocking morpholino oligomers (MOs) reduce PTPo mRNA expression at 2 weeks post-transection (TX). (A) Schematic of wild type lamprey PTPo with the genomic sequence targeted by the MOs. (B) Schematic of morphant PTPo showing the premature stop codon produced by exon skipping. (C) Schematic of flat-mounted larval lamprey brain showing the identified RS neurons ("good regenerators," blue; "bad regenerators," red). (D,E) Representative micrographs of wholemount brain in situ hybridization using a PTPo RNA probe at 2 weeks post-TX. (F) Contingency analysis with Fisher's Exact Test on all counted cells. Significantly fewer RS neurons treated with MOPTPo were positive for PTPo mRNA than controls. (G-I) Analysis with student's $t$-tests revealed that significantly fewer bad regenerators treated with MOPTPo $(n=8)$ were positive for PTP $\sigma$ than were those treated with $\mathrm{MO}_{\mathrm{C} \text { trl }}(n=7)$. Error bars show SEM. ${ }^{*} p<0.05$; *** $p<0.001 ;$ n.s., non-significant.

so as to label surviving identified RS neurons. The analysis revealed that the MO fluorescence almost perfectly co-labeled with the dextran dye. Quantitatively, this manifested as a strong positive correlation between the numbers of neurons labeled during each TX ( $r=0.97, n=5$ lampreys total). This confirmed that the MO labeling persists even at extended time points, supporting the use of MO labeling as a proxy for cell survival. Since transfection efficiency was comparable between the control- and PTP $\sigma$-targeting MOs at 1-month post-TX, loss of MO-labeling at extended timepoints reflected genuine cell loss, and was not a result of differences in labeling efficiency or stability.

\section{PTPo Knockdown Did Not Enhance TX-Induced Caspase Activation}

In lampreys, TX induces a delayed form of apoptotic retrograde death among "bad regenerator" identified RS neurons (Shifman et al., 2008). Because the reduction in cell survival observed

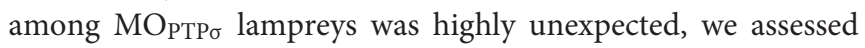

the post-TX time course of apoptosis signaling to determine if the observed cell loss was due to enhanced caspase activity. After PTP $\sigma$ knockdown, we processed wholemount lamprey brains for activated caspases with poly caspase FLICA at 2, 4, 7, 10 and 20 weeks post-TX (Figure 4). In this cohort, significant identified RS neuron loss was seen in MO animals at 20 weeks post-TX, but not at earlier time points. Surprisingly, this cell loss was not preceded by enhanced caspase activation.

\section{PTP $\sigma$ Knockdown Did Not Enhance Akt Phosphorylation or p53 Abundance}

The molecular intermediaries in the LAR-family RPTP signaling pathway are still not completely known. The primary downstream effect of CSPG-PTP $\sigma$ signaling is believed to be activation of the small GTPase, RhoA, which regulates cytoskeletal dynamics via its associated kinase, ROCK (Ohtake et al., 2016). An additional, but important consequence of CSPG-induced LAR-family RPTP activation 

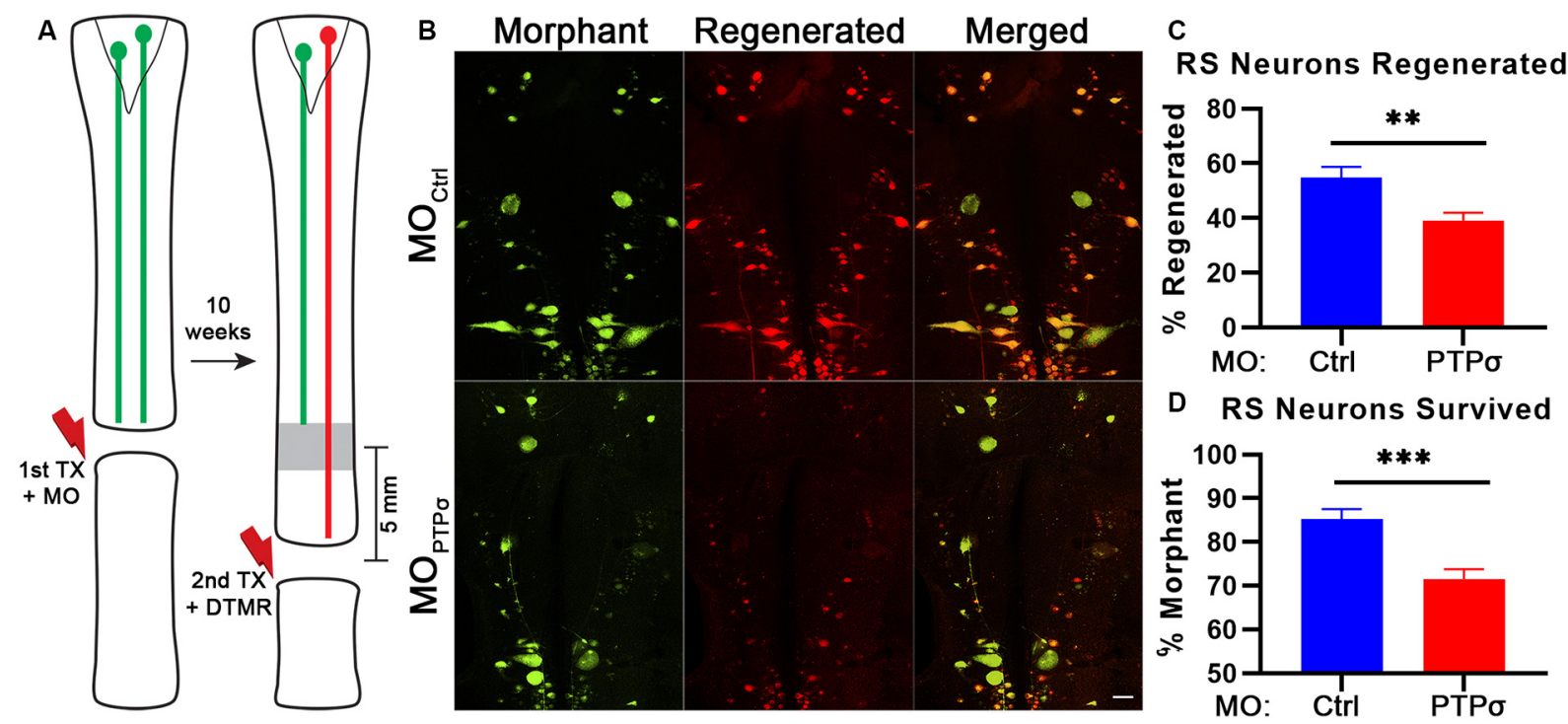

FIGURE 2 | PTP $\sigma$ knockdown impaired axon regeneration and long-term neuron survival. (A) Schematic of retrograde labeling procedure. At 10 weeks after TX and MO application, lampreys were subjected to a second TX, $5 \mathrm{~mm}$ caudal to the first, and regenerated axons were back labeled with DTMR. (B) Representative whole mounted brain maximum intensity projection confocal micrographs of MO-Ctrl or MOPTPo (green) and DTMR (red) labeled RS neurons ( $n=10-12$ animals). Scale, $100 \mu \mathrm{m}$. (C-D) Quantification of identified RS neuron regeneration (DTMR) and survival (MO-fluorescein). Statistical analysis performed with two-tailed student's $t$-tests. Error bars show SEM. ${ }^{* *} p<0.01 ;{ }^{* * *} p<0.001$.

is inhibition of the pro-survival, pro-growth Akt pathway, likely via ROCK but potentially through RhoA-independent mechanisms. This second effect may be particularly important because, at least in lampreys, axon regeneration in the CNS appears to be accomplished in the absence of F-actinfilled growth cones (Lurie et al., 1994). Moreover, since Akt regulates cell survival following PTP $\sigma$ knockdown, its activity is especially relevant, given the observed loss of axotomized RS neurons following PTP $\sigma$ knockdown. To assess Akt activity, Western blots were performed on lamprey brains and spinal cords. Contrary to our original hypothesis, but consistent with RS neuronal loss, we did not observe increases in phospho-Akt (Thr308) levels among $\mathrm{MO}_{\mathrm{PTP} \sigma}$-treated lampreys, 2 weeks post-TX, in both brains and spinal cords extending from approximately the second gill to $0.5 \mathrm{~cm}$ below the TX. If anything, in both the brain and spinal cord, the relative abundance of activated Akt was reduced, though this did not reach statistical significance (Figure 5). Additionally, total Akt levels were unchanged relative to controls.

Given the unexpectedness of PTP $\sigma$ knockdown-associated cell death, it was important to consider off-target effects. In zebrafish, off-target MO toxicity typically is p53-dependent (Bedell et al., 2011; Gerety and Wilkinson, 2011). Although p53 is complexly regulated, a major consequence of activation is a several-fold increase in protein half-life (Giaccia and Kastan, 1998). Thus, to assess p53 activation in our model, we assessed p53 abundance with Western Blot and immunofluorescence 2 weeks after TX and MO transfection (Figure 6). Overall, p53 abundance in lamprey brains was low, with expression primarily restricted to the ependymal cells lining the ventricles.
No appreciable differences were observed between animals treated with the control or PTP $\sigma$-targeting MO. Likewise, Western Blot analysis showed similar levels of p53 expression between both groups of brain homogenates. Although these results cannot conclusively rule out all potential off-target effects, they do exclude the most common pathway for cell-autonomous MO toxicity. Additionally, the long delay between confirmed MO biological activity in this study (i.e., within 2 weeks post-TX) and neuron loss (10-20 weeks post-TX) seems uncharacteristic of acute toxicity. Finally, it is important to note, that MOs have been used repeatedly in lamprey studies, and, to date, no off-target effects have been reported (Zhang et al., 2015; Hu et al., 2017; Sobrido-Cameán et al., 2019).

\section{PTPo Knockdown Attenuated the Local Immune Response to TX}

Although MO transfection in the brain was limited to those RS neurons whose axons extended to at least the 5th gill, it was possible that РТР $\sigma$-expressing cells adjacent to the TX, including resident microglia and infiltrating macrophages, were incidentally transfected. As perturbations to the inflammatory response could contribute to the RS cell loss observed after PTP $\sigma$ knockdown, we assessed the number of microglial profiles present in horizontal spinal cord sections, extending $600 \mu \mathrm{m}$ rostral of the TX, 2 weeks after injury (Figure 7). Unexpectedly, we observed a significant reduction in the number of microglial profiles in the spinal cords of lampreys treated with MOPTPo. This suggests that PTP $\sigma$ knockdown may have attenuated the inflammatory response to SCI. 

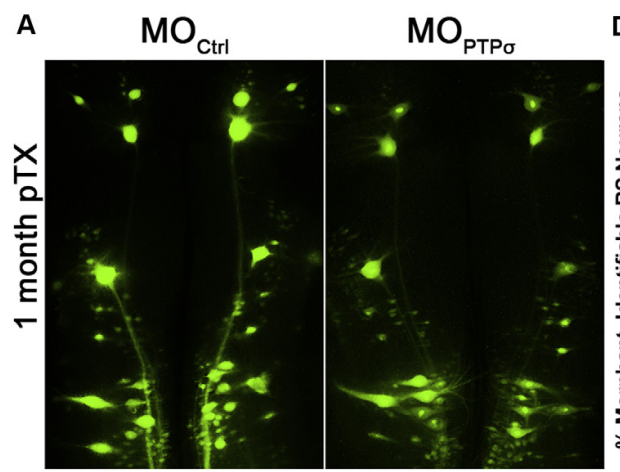

\section{D}

\section{E}

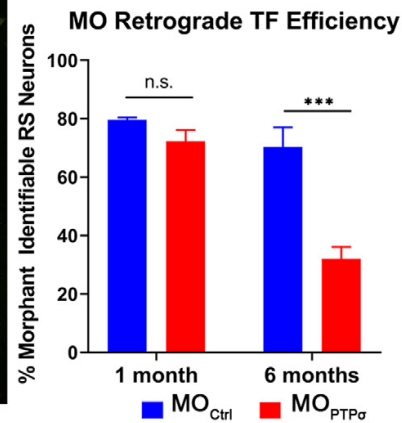

$\%$ Labeled Identifiable Neurons

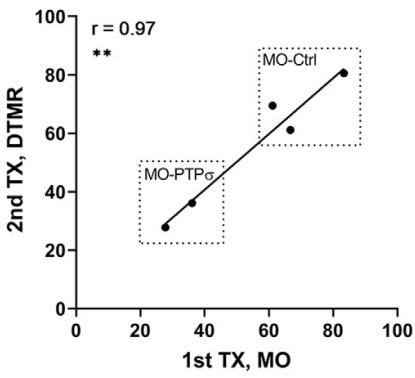

B

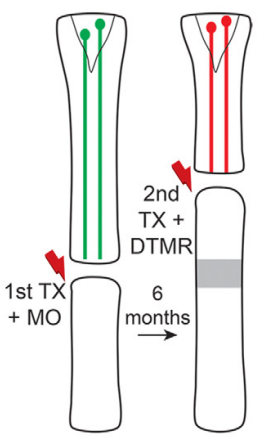

$\begin{array}{lll}\text { C } & \text { 1st TX } & \mathrm{MO}_{\mathrm{ctrl}} \text { 2nd TX }\end{array}$

1st TX

$\mathrm{MO}_{\mathrm{PTPG}}$

2nd TX

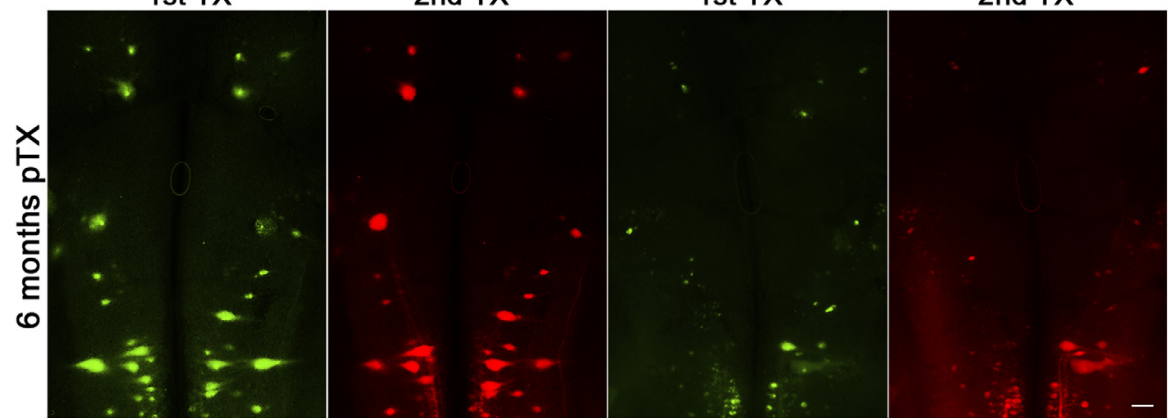

FIGURE 3 | Morpholino labeling is a persistent proxy for cell survival. (A) Representative micrographs of fluorescent-MO labeling among RS neurons, 1 month after TX and MO application. (B) Experiment schematic for labeling surviving RS neurons. Six months after TX and transfection with MOPTPo $(n=2)$ or MO $\mathrm{Ctrl}_{\text {( }}(n=3)$, a second TX was made rostral to the first, close to the brain, and surviving RS neurons were back labeled with DTMR. (C) Representative micrographs of whole mounted lamprey brains showing MO transfected RS neurons (1st TX) and surviving RS neurons labeled by DTMR (2nd TX). Scale, 100 $\mu$ m. (D) At 1 month post-TX, RS neurons transfection efficiency between $\mathrm{MO}_{\mathrm{Ctrl}}(n=9)$ and MOPTPo $(n=8)$ are comparable, approximately $72-80 \%$ of identified neurons. However, at 6 months post-TX, MO $\mathrm{M}_{\text {Crl }}$ persists in $70 \%$ of RS neurons while $\mathrm{MO}$ is present in only $32 \%$. The analysis was performed with two-way ANOVA with a post hoc Sidak test. Error bars show SEM. ${ }^{* * *} p<0.001$. (E) Pearson's correlation analysis revealed a strong positive correlation between labeling from the 1 st and 2 nd TX at 6 months. Thus, the reduction in MOPTPo labeling is from genuine cell loss and not degradation of the MO. ${ }^{* *} p<0.01$; n.s., non-significant.

\section{PTP $\sigma$ Knockdown Modestly Impaired Behavioral Recovery From TX}

In lampreys, behavioral recovery of coordinated swimming after TX is mediated by true axon regeneration (Selzer, 1978). However, the role of the identified RS neurons in restoring locomotion is less clear. Although under certain conditions, stimulation of these neurons may elicit movement, partial injury models suggest that they are not necessary to initiate locomotion (Rovainen, 1967; McClellan, 1988). Thus, it is not currently possible to associate behavioral recovery with anatomical regeneration of specific neurons. Nevertheless, swimming recovery after TX is a useful correlate for regenerative and plastic processes in toto, as well as a reflection of overall animal health.

One of the more common approaches to assess swimming recovery is the use of semiquantitative locomotion scales, which vary slightly from study-to-study (Ayers, 1988; Herman et al., 2018). In the present report, locomotion quality was assessed during $2 \mathrm{~min}$ of free swim recorded 3 days per week, 1 week before the injury and up to 10 weeks after TX, using a locomotion recovery scale, which assessed qualitative aspects of lamprey swimming on a five point scale (Figure 8). Uninjured lampreys are efficient swimmers and consistently maintained an upright dorsal-ventral posture (score 5). After injury, lampreys were paralyzed below the injury (score 0) but, during the first few weeks of recovery, experienced tonic body flexion movements below the lesion (score 1) and gained the ability to propel themselves forward short distances (stage 2). By 4 weeks post-injury, lampreys recovered the ability to swim but are unable to maintain proper dorsal-ventral posture (scores 3 and 4). Although dorsal-ventral posture improved gradually, swimming remained abnormal for at least 10 weeks post-TX. No differences in swimming quality were observed between $\mathrm{MO}_{\mathrm{Ctrl}}$ and MOPTP $\sigma$ lampreys.

To increase the sensitivity of our swimming assay, we used ANY-maze software (Stoelting) to quantify kinematic parameters including maximum speed, total distance traveled, and latency to immobility. Notably, our observation of the maximum swimming speed of approximately three body lengths seconds $^{-1}$ in uninjured lampreys was consistent with previous reports (Gemmell et al., 2016). As with the semiquantitative assessment, deficits were clearly observed immediately following TX but improved over the following 


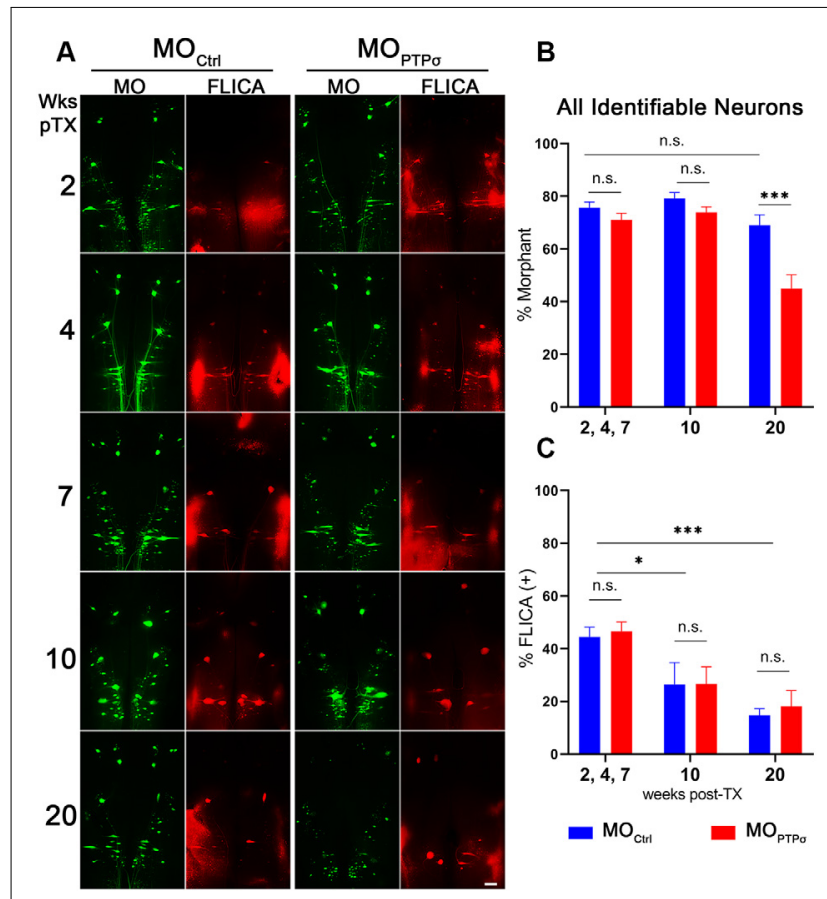

FIGURE 4 | PTP $\sigma$ knockdown-mediated reduction in neuronal survival was not accompanied by enhanced caspase activation. (A) Representative whole mounted brain widefield fluorescence micrographs of RS neurons labeled with $\mathrm{MO}_{\text {ctrl }}$ or MOpTPo (green) and poly caspase FLICA (red) after TX. Scale bar, $200 \mu \mathrm{m}$. Quantification of $\mathrm{MO}$ labeling (B) and MO+FLICA

double-labeling (C) among all identified RS neurons ( $n=5-9$ lampreys per group per time point). Despite exacerbated cell loss, enhanced caspase activation was not detected following TX and PTP $\sigma$ KD. Statistical analysis performed with two-way ANOVA and Sidak post hoc multiple comparisons test. Error bars show SEM. ${ }^{*} p<0.05$; ${ }^{* * *} p<0.001$; n.s., non-significant.

weeks. Interestingly, during late recovery, maximum speed approximated control levels despite persistent deficits in the righting response. Total distance traveled remained minimal after TX until 4 weeks when swimming ability returned but continued to remain below baseline for the duration of the study. Latency to immobility showed deficits before 4 weeks but afterward approximated baseline. Although modest deficits were observed in total swim distance and latency to immobility, it is clear that PTPo knockdown did not grossly alter behavioral recovery following TX.

\section{DISCUSSION}

Contrary to our original hypothesis, knocking down lamprey PTP $\sigma$ with antisense MOs reduced, rather than improved, RS axon regeneration and cell survival after TX. Indeed, beginning at 10 weeks post-TX, PTP $\sigma$ knockdown significantly reduced survival of the identified RS neurons. This delay in effect is comparable to the long delay in TX-induced apoptosis previously reported among the poorly-regenerating RS neurons (Shifman et al., 2008). Typically, this injury-induced supraspinal cell death is preceded by activation of caspases, which can be detected
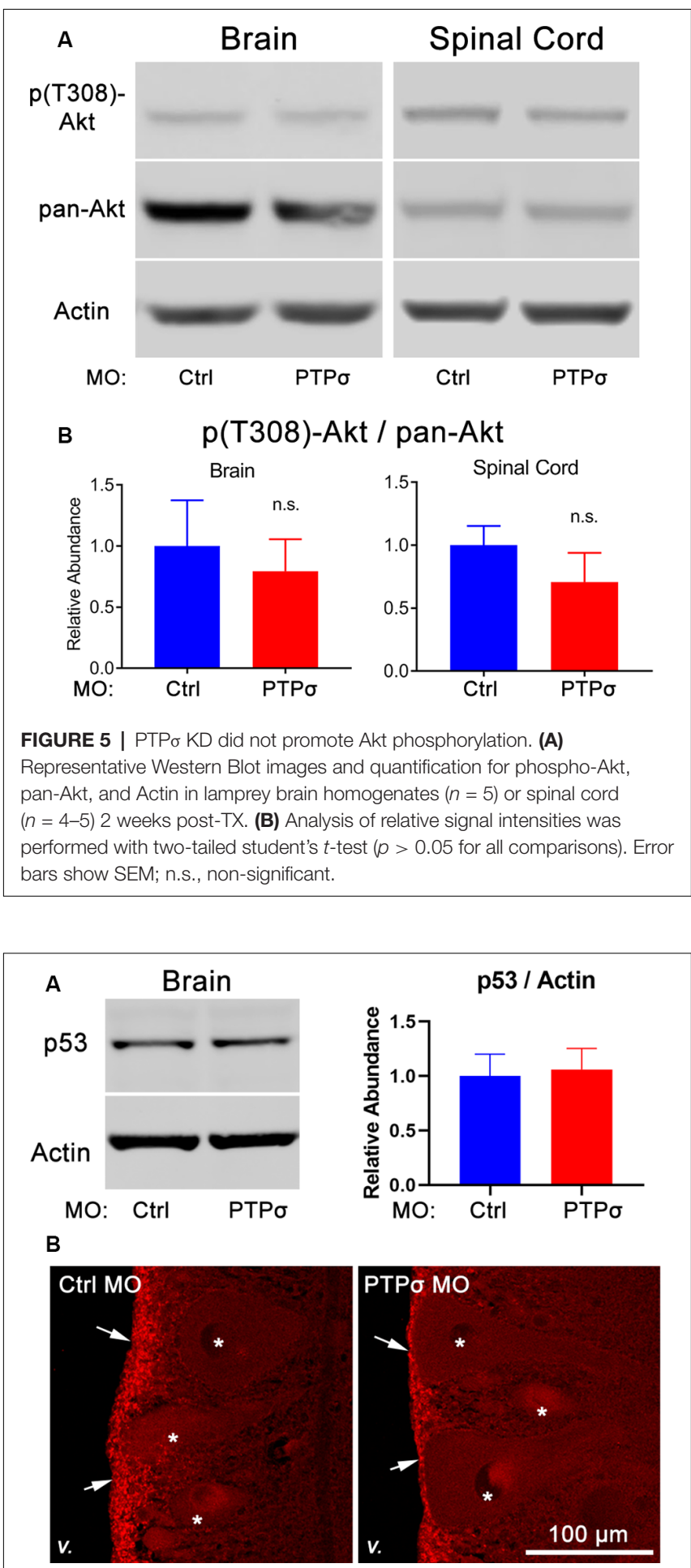

FIGURE 6 | MOPTP transfection did not promote p53 activation. (A) Representative Western Blot image and quantification for p53 and actin in lamprey brain homogenates $(n=4-5)$. (B) Representative confocal maximum intensity projections of p53 immunofluorescence in lamprey hindbrain sections (v., 4th ventricle; arrows, ependyma; *reticulospinal neurons).

within cell bodies as early as 2 weeks post-TX (Barreiro-Iglesias and Shifman, 2012; Hu et al., 2013). However, in the present 


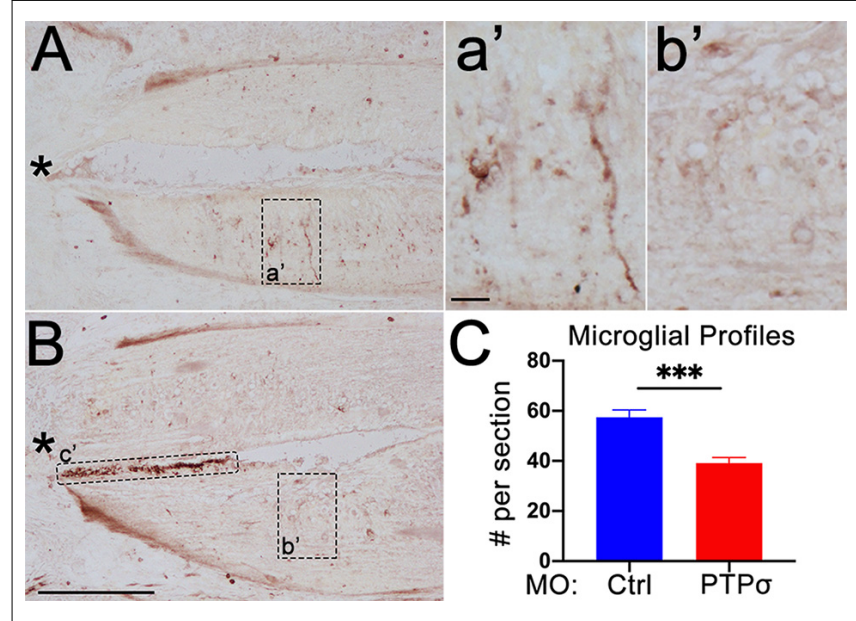

FIGURE 7 | PTP $\sigma$ knockdown attenuated the local immune response to TX. (A,B) Representative micrographs of IB4 staining in rostral horizontal spinal cord sections from $\mathrm{MO}_{\mathrm{Ctrl}}\left(\mathbf{A}, \mathbf{a}^{\prime}\right)$ and $\mathrm{MO}_{\text {PTPo }}$ (B,, b') lampreys 2 weeks pTX. Infiltrating macrophages in the central canal (c') were excluded from the analysis. (C) On mean, fewer IB4+ microglia were present in sections from $\mathrm{MO}$ spinal cords ( $n=2$ animals, eight sections) than $\mathrm{MO}_{\mathrm{Ctrl}}$ spinal cords ( $n=3$ animals, 12 sections). Analysis was performed with a two-tailed student's $t$-test. Error bars show SEM. ${ }^{* * *} p<0.001$. Scale, $200 \mu \mathrm{m}(\mathbf{A}, \mathbf{B})$, $20 \mu \mathrm{m}\left(\mathbf{a}^{\prime}, \mathbf{b}^{\prime}\right)$. * $\mathrm{TX}$.

study, exacerbated cell death following PTP $\sigma$ knockdown was not accompanied by a similar increase in the activation of caspases. Although effects on swimming recovery were modest, the changes were in the same direction as the reduction in cell survival and axon regeneration. PTP $\sigma$ knockdown did not induce significant changes in Akt phosphorylation in the brain or spinal cord lysates.

Although this study did not identify the mechanism by which PTP $\sigma$ knockdown enhanced TX-induced cell death, the findings indicate that PTP $\sigma$ does not significantly suppress RS axon regeneration in lampreys. This interpretation runs contrary to the putative role of PTP $\sigma$ as an important receptor mediating the axon growth-inhibiting effects of CSPGs in mammalian SCI. However, there are a number of on-target cell-autonomous and non-autonomous mechanisms that may explain our findings, as discussed below.

\section{PTPo Interactions With CSPGs and HSPGs}

Like SCI in mammals, lamprey TX results in "scar" formation around the lesion. In mammals, the scar is characterized by a glia limitans of reactive astrocytes surrounding a fibrotic core (Wanner et al., 2013). In lampreys, the primary feature of the lamprey scar is an enlarged central canal and realignment of glial processes from a transverse to longitudinal alignment, which bridges proximal and distal spinal stumps (Yin and Selzer, 1983; Lurie et al., 1994). In both cases, the scar is rich in growth-inhibiting CSPGs (Lander et al., 1998; McKeon et al., 1999; Stichel et al., 1999; Thon et al., 2000; Jones et al., 2002, 2003; Zhang et al., 2014). Receptors on axon tips, including the LAR-family RPTPs, PTP $\sigma$, and LAR; as well as the myelin-associated inhibitor receptors, NgR1 and NgR3, are believed interact with extracellular CSPGs to induce growth

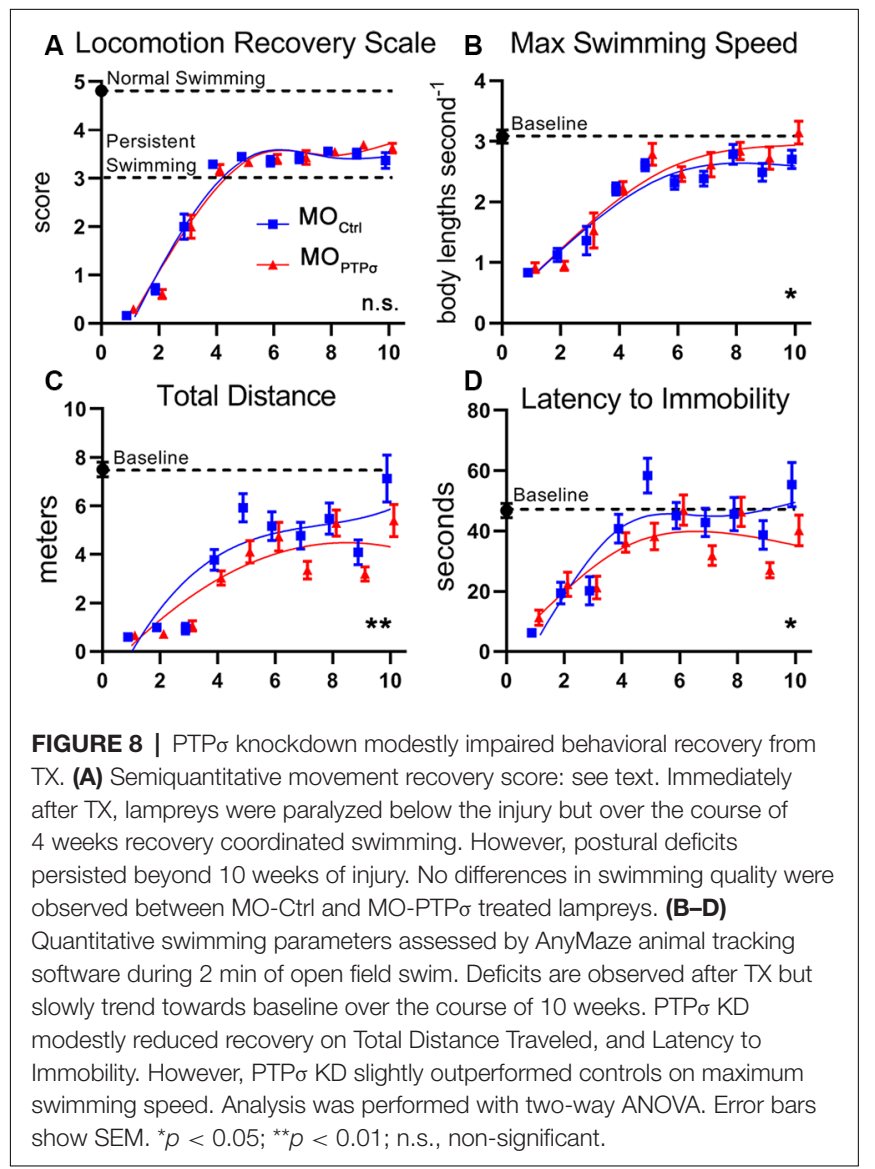

cone collapse, halting axon outgrowth (Shen et al., 2009; Fisher et al., 2011; Dickendesher et al., 2012). PTP $\sigma$ and LAR generally colocalize among lamprey bad regenerator RS neurons (Zhang et al., 2014; Rodemer et al., 2015). Lamprey RS neurons also express an NgR homolog, although its distribution has yet to be well characterized (unpublished observations). Thus, it possible that any regeneration promoting effects of PTP $\sigma \mathrm{KD}$ was compensated for by other CSPG receptors.

Alternatively, HSPGs compete with CSPGs for PTP $\sigma$ binding. Unlike growth-inhibitory CSPGs, HSPGs-PTP $\sigma$ interactions promote neurite outgrowth, although the mechanism remains unclear. In vitro studies suggest PTP $\sigma-\mathrm{HSPG}$ interactions stabilize the receptor in tight clusters on the plasma membrane resulting in uneven distribution of intracellular phosphatase activity (Coles et al., 2011). However, other studies suggest both CSPGs and HSPGs induce clustering but that HSPGs interact with PTP $\sigma$ via a secondary binding site (Katagiri et al., 2018). Regardless of the exact mechanism, HSPGs-PTP $\sigma$ interactions may predominate the lamprey spinal cord resulting in PTP $\sigma$ having a net pro-growth, pro-survival role after TX. Moreover, the sulphation patterns on the CSPG GAG side chains are believed to greatly influence receptor interactions. Notably, PTP $\sigma$ has been shown to preferentially interact with di-sulfated CSPGs and only weakly interact with mono-sulfated CSPGs, including CS-C, the dominant CSPG species in the glial scar (Katagiri et al., 2018; Tadai et al., 2018). While CSPGs in the 
mammalian glial scar may contain sufficient GAG diversity to preserve PTP $\sigma$ binding, CSPGs in lampreys remain largely uncharacterized. Thus, depending on sulphation patterns, it is possible that lamprey PTP $\sigma$ does not strongly interact with the CSPG scar.

\section{The Role of PTP $\sigma$ in Non-neuronal Cells}

Although most studies on PTP $\sigma$ have focused on neuronintrinsic effects, РTP $\sigma$ is also expressed in non-neuronal cells. Reports have suggested that CSPGs antagonize neural progenitor and oligodendrocyte precursor cell survival, proliferation, and differentiation, which can be rescued by deleting PTP $\sigma$ or inhibiting receptor function with peptides (Dyck et al., 2015, 2019; Zhong et al., 2019). Notably, PTP $\sigma$ is also expressed within the immune system among subpopulations of dendritic cells and, in lower levels among T-cells and microglia (Bunin et al., 2015; Ohtake et al., 2017). While the lamprey immune system is unique, it includes analogs to mammalian immune components including B- and T-like cells, and microglia (Laramore et al., 2011; Hirano et al., 2013). In this study, MO-transfection in the brain was clearly limited to neurons with projections extending at least to the 5th gill. However, it was possible that the application of MO to the spinal cord stump incidentally transfected local populations, reducing PTP $\sigma$ expression on those cells and, consequently, altering their response to TX. Using isolectin B4 staining, we observed a significant reduction in the number of microglial profiles present in the spinal cord at, and adjacent to the TX in PTPo knockdown lampreys, which suggests a possible attenuated immune response to injury. However, our approach did not distinguish small microglial cell bodies from large, transversely sectioned microglial processes, so the apparent reduction in microglia number might be due to differences in the activation state of microglia, rather than to reductions in microglial proliferation or infiltration. Moreover, the question of whether this perturbation to the immune response is beneficial or detrimental to neuron survival and regeneration is not yet determined.

Interestingly, there are conflicting reports in mammals as to whether PTP $\sigma$ inhibition reduces or promotes inflammation. In a mouse MOG-induced model of experimental allergic encephalomyelitis (EAE), genetic deletion of PTP $\sigma$ exacerbated inflammation within the spinal cord, resulting in increased infiltration of CD4+ T-cells, activation of macrophages, and upregulation of the pro-inflammatory cytokines, which led to enhanced axon damage and worsened clinical outcome (Ohtake et al., 2017). However, in another EAE report, which utilized intraperitoneal injection of blocking peptides, PTP $\sigma$ inhibition reduced inflammation and improved clinical EAE scores (Luo et al., 2018). In a rat clip-compression model of SCI, PTPo blocking peptides shifted immune response from pro- to anti-inflammatory, including upregulation of anti-inflammatory cytokines and increased activation of "M2" microglia and T-regulatory cells (Dyck et al., 2018). In that study, while there was a shift in the microglial activation state towards M2, no change was observed in total microglia number. In the present study, although the exact significance of the reduction in microglial density associated with PTP $\sigma$ knockdown has not yet been established, the findings suggest that non-autonomous processes at the site of injury may have contributed to impaired supraspinal RS neuron survival following PTP $\sigma$ knockdown.

\section{Alternative Cell-Autonomous Effects}

During neural development, LAR-family RPTPs, including РТР $\sigma$, function as important organizers of excitatory synaptogenesis (Han et al., 2018; Südhof, 2018; Bomkamp et al., 2019). In vitro and biochemical studies suggest that presynaptic PTP $\sigma$ forms a trans-synaptic adhesion complex with postsynaptic proteins via its Ig-like and fibronectin-type III extracellular domains. These postsynaptic proteins include NGL-3, TrkC, IL1RAPL1, IL1RAcP, Slitrk 1-6, and SALM-3 (Takahashi et al., 2011; Yoshida et al., 2011, 2012; Um et al., 2014; Li et al., 2015). Although studies with primary neuronal cultures have shown that PTP $\sigma$ impairs synapse formation in vitro, evidence has been lacking in vivo (Han et al., 2018). Notably, in a recent study using an AP-tagged fusion construct in mouse brain tissue slices, РТР neurons, and binding persisted even after CSPGs and HSPGs were enzymatically digested (Yi et al., 2014). Although it remains unclear whether PTP $\sigma$ deficiency impairs regenerative synaptogenesis in vivo, it is possible that this may have contributed to the neuron loss observed in our model via trophic deprivation.

Alternatively, an RNAi screen in U2OS cells has implicated PTP $\sigma$ as a negative regulator of autophagy (Martin et al., 2011). In these cells, PTP $\sigma$ inhibition hyperactivated both constitutive and induced autophagic pathways by relieving downregulation of phosphatidylinositol-3-phosphate (PtdIns3P), a critical lipid involved in the formation of autophagic vesicles. Although cell death was not reported in that study, it is possible that prolonged PTP $\sigma$ deficiency promotes aberrant hyperactivation of autophagy pathways in vivo. Thus, non-apoptotic, autophagydependent mechanisms may have driven cell death following PTP $\sigma$ knockdown in our model (Denton and Kumar, 2019). Obviously, further investigations will be needed to test these hypotheses.

\section{CONCLUSION}

The results from this study suggest that PTP $\sigma$ is not a net negative regulator of axon regeneration in the RS neurons of lamprey. Although this result is not consistent with the putative role of PTP $\sigma$ in mammal axon regeneration, it can potentially be explained by known cell-autonomous or non-autonomous mechanisms. In this report, РTP $\sigma$ knockdown significantly reduced regeneration and antagonized RS neuron survival beginning between 10 and 20 weeks post-TX. This cell loss was not accompanied by enhanced caspase activation. To our knowledge, PTP $\sigma$ deletion has not been previously implicated in neuron death; nor, however, has it been shown to be neuroprotective. For example, following optic nerve crush, PTP $\sigma$ deletion reportedly improved axon regeneration but did not prevent retinal ganglion cell death (Sapieha et al., 2005). The lack of activated caspases and long latency suggest the possibility 
that enhanced supraspinal neuron death following MO-induced PTP $\sigma$ knockdown resulted from non-apoptotic mechanisms.

\section{DATA AVAILABILITY STATEMENT}

The datasets generated for this study are available on request to the corresponding author.

\section{ETHICS STATEMENT}

The animal study was reviewed and approved by Temple University's Institutional Animal Care and Use Committee.

\section{AUTHOR CONTRIBUTIONS}

WR designed, performed, and analyzed the experiments, and wrote the first draft of the manuscript. GZ designed and performed experiments. IS and LJ performed experiments. JH

\section{REFERENCES}

Ayers, J. (1988). "Recovery of oscillator function following spinal regeneration in the sea lamprey," in Neuronal and Cellular Oscillators, ed. J. W. Jacklet (New York, NY: Marcel Dekker Inc.), 371-404.

Barreiro-Iglesias, A., and Shifman, M. I. (2012). Use of fluorochromelabeled inhibitors of caspases to detect neuronal apoptosis in the wholemounted lamprey brain after spinal cord injury. Enzyme Res. 2012:835731. doi: $10.1155 / 2012 / 835731$

Barritt, A. W., Davies, M., Marchand, F., Hartley, R., Grist, J., Yip, P., et al. (2006). Chondroitinase $\mathrm{ABC}$ promotes sprouting of intact and injured spinal systems after spinal cord injury. J. Neurosci. 26, 10856-10867. doi: 10.1523/JNEUROSCI.2980-06.2006

Bedell, V. M., Westcot, S. E., and Ekker, S. C. (2011). Lessons from morpholino-based screening in zebrafish. Brief. Funct. Genomics 10, 181-188. doi: 10.1093/bfgp/elr021

Bomkamp, C., Padmanabhan, N., Karimi, B., Ge, Y., Chao, J. T., Loewen, C. J. R., et al. (2019). Mechanisms of ptp $\sigma$-mediated presynaptic differentiation. Front. Synaptic Neurosci. 11:17. doi: 10.3389/fnsyn.2019. 00017

Bradbury, E. J., Moon, L. D., Popat, R. J., King, V. R., Bennett, G. S., Patel, P. N., et al. (2002). Chondroitinase ABC promotes functional recovery after spinal cord injury. Nature 416, 636-640. doi: 10.1038/416636a

Bunin, A., Sisirak, V., Ghosh, H. S., Grajkowska, L. T., Hou, Z. E., Miron, M., et al. (2015). Protein tyrosine phosphatase PTPRS is an inhibitory receptor on human and murine plasmacytoid dendritic cells. Immunity 43, 277-288. doi: 10.1016/j.immuni.2015.07.009

Chagnon, M. J., Uetani, N., and Tremblay, M. L. (2004). Functional significance of the LAR receptor protein tyrosine phosphatase family in development and diseases. Biochem. Cell Biol. 82, 664-675. doi: 10.1139/o04-120

Cohen, L. D., Zuchman, R., Sorokina, O., Müller, A., Dieterich, D. C., Armstrong, J. D., et al. (2013). Metabolic turnover of synaptic proteins: kinetics, interdependencies and implications for synaptic maintenance. PLoS One 8:e63191. doi: 10.1371/journal.pone.0063191

Coles, C. H., Shen, Y., Tenney, A. P., Siebold, C., Sutton, G. C., Lu, W., et al. (2011). Proteoglycan-specific molecular switch for RPTP $\sigma$ clustering and neuronal extension. Science 332, 484-488. doi: 10.1126/science.1200840

Denton, D., and Kumar, S. (2019). Autophagy-dependent cell death. Cell Death Differ. 26, 605-616. doi: 10.1038/s41418-018-0252-y

Dickendesher, T. L., Baldwin, K. T., Mironova, Y. A., Koriyama, Y., Raiker, S. J., Askew, K. L., et al. (2012). NgR1 and NgR3 are receptors for chondroitin sulfate proteoglycans. Nat. Neurosci. 15, 703-712. doi: 10.1038/nn.3070

Dyck, S. M., Alizadeh, A., Santhosh, K. T., Proulx, E. H., Wu, C. L., and Karimi-Abdolrezaee, S. (2015). Chondroitin sulfate proteoglycans negatively performed experiments and contributed to the writing of the manuscript. SL contributed to the experimental design and suggested specific experiments. MS designed experiments and contributed to writing the manuscript.

\section{FUNDING}

This work was funded by the following grants: National Institute of Neurological Disorders and Stroke (NINDS), R01NS092876, R01NS105961，1R01NS079432; National Eye Institute (NEI), 1R01EY024575; and Shriners Hospitals for Children, SHC85400 .

\section{ACKNOWLEDGMENTS}

We thank Ms. Cynthia Laramore for contributions to PTPo cloning; and the respective laboratories of Drs. Michael Shifman and Tanya Ferguson for material and equipment contributions.

modulate spinal cord neural precursor cells by signaling through LAR and RPTP $\sigma$ and modulation of the Rho/ROCK pathway. Stem Cells 33, 2550-2563. doi: 10.1002/stem.1979

Dyck, S., Kataria, H., Akbari-Kelachayeh, K., Silver, J., and Karimi-Abdolrezaee, S. (2019). LAR and PTP $\sigma$ receptors are negative regulators of oligodendrogenesis and oligodendrocyte integrity in spinal cord injury. Glia 67, 125-145. doi: 10.1002/glia.23533

Dyck, S., Kataria, H., Alizadeh, A., Santhosh, K. T., Lang, B., Silver, J., et al. (2018). Perturbing chondroitin sulfate proteoglycan signaling through LAR and PTP $\sigma$ receptors promotes a beneficial inflammatory response following spinal cord injury. J. Neuroinflammation 15:90. doi: 10.1186/s12974-018$1128-2$

Fisher, D., Xing, B., Dill, J., Li, H., Hoang, H. H., Zhao, Z., et al. (2011). Leukocyte common antigen-related phosphatase is a functional receptor for chondroitin sulfate proteoglycan axon growth inhibitors. J. Neurosci. 31, 14051-14066. doi: 10.1523/JNEUROSCI.1737-11.2011

Fry, E. J., Chagnon, M. J., López-Vales, R., Tremblay, M. L., and David, S. (2010). Corticospinal tract regeneration after spinal cord injury in receptor protein tyrosine phosphatase $\sigma$ deficient mice. Glia 58, 423-433. doi: 10.1002/glia. 20934

Gemmell, B. J., Fogerson, S. M., Costello, J. H., Morgan, J. R., Dabiri, J. O., and Colin, S. P. (2016). How the bending kinematics of swimming lampreys build negative pressure fields for suction thrust. J. Exp. Biol. 219, 3884-3895. doi: $10.1242 /$ jeb. 144642

Gerety, S. S., and Wilkinson, D. G. (2011). Morpholino artifacts provide pitfalls and reveal a novel role for pro-apoptotic genes in hindbrain boundary development. Dev. Biol. 350, 279-289. doi: 10.1016/j.ydbio.2010.11.030

Giaccia, A. J., and Kastan, M. B. (1998). The complexity of p53 modulation: emerging patterns from divergent signals. Genes Dev. 12, 2973-2983. doi: 10.1101/gad.12.19.2973

Han, K. A., Ko, J. S., Pramanik, G., Kim, J. Y., Tabuchi, K., Um, J. W., et al. (2018). PTPo drives excitatory presynaptic assembly via various extracellular and intracellular mechanisms. J. Neurosci. 38, 6700-6721. doi: 10.1523/JNEUROSCI.0672-18.2018

Herman, P. E., Papatheodorou, A., Bryant, S. A., Waterbury, C. K. M., Herdy, J. R., Arcese, A. A., et al. (2018). Highly conserved molecular pathways, including Wnt signaling, promote functional recovery from spinal cord injury in lampreys. Sci. Rep. 8:742. doi: 10.1038/s41598-01718757-1

Hirano, M., Guo, P., McCurley, N., Schorpp, M., Das, S., Boehm, T., et al. (2013). Evolutionary implications of a third lymphocyte lineage in lampreys. Nature 501, 435-438. doi: 10.1038/nature12467

Houle, J. D., Tom, V. J., Mayes, D., Wagoner, G., Phillips, N., and Silver, J. (2006). Combining an autologous peripheral nervous system "bridge" and matrix 
modification by chondroitinase allows robust, functional regeneration beyond a hemisection lesion of the adult rat spinal cord. J. Neurosci. 26, 7405-7415. doi: 10.1523/JNEUROSCI.1166-06.2006

Hu, J., Zhang, G., Rodemer, W., Jin, L. Q., Shifman, M., and Selzer, M. E. (2017). The role of RhoA in retrograde neuronal death and axon regeneration after spinal cord injury. Neurobiol. Dis. 98, 25-35. doi: 10.1016/j.nbd.2016.11.006

$\mathrm{Hu}$, J., Zhang, G., and Selzer, M. E. (2013). Activated caspase detection in living tissue combined with subsequent retrograde labeling, immunohistochemistry or in situ hybridization in whole-mounted lamprey brains. J. Neurosci. Methods 220, 92-98. doi: 10.1016/j.jneumeth.2013.08.016

Jones, L. L., Margolis, R. U., and Tuszynski, M. H. (2003). The chondroitin sulfate proteoglycans neurocan, brevican, phosphacan, and versican are differentially regulated following spinal cord injury. Exp. Neurol. 182, 399-411. doi: 10.1016/s0014-4886(03)00087-6

Jones, L. L., Yamaguchi, Y., Stallcup, W. B., and Tuszynski, M. H. (2002). NG2 is a major chondroitin sulfate proteoglycan produced after spinal cord injury and is expressed by macrophages and oligodendrocyte progenitors. J. Neurosci. 22, 2792-2803. doi: 10.1523/JNEUROSCI.22-07-02792.2002

Katagiri, Y., Morgan, A. A., Yu, P., Bangayan, N. J., Junka, R., and Geller, H. M. (2018). Identification of novel binding sites for heparin in receptor proteintyrosine phosphatase (RPTP $\sigma)$ : implications for proteoglycan signaling. J. Biol. Chem. 293, 11639-11647. doi: 10.1074/jbc.RA118.003081

Lander, C., Zhang, H., and Hockfield, S. (1998). Neurons produce a neuronal cell surface-associated chondroitin sulfate proteoglycan. J. Neurosci. 18, 174-183. doi: 10.1523/JNEUROSCI.18-01-00174.1998

Lang, B. T., Cregg, J. M., DePaul, M. A., Tran, A. P., Xu, K., Dyck, S. M., et al. (2015). Modulation of the proteoglycan receptor PTP $\sigma$ promotes recovery after spinal cord injury. Nature 518, 404-408. doi: 10.1038/nature13974

Laramore, C., Maymind, E., and Shifman, M. I. (2011). Expression of neurotrophin and its tropomyosin-related kinase receptors (Trks) during axonal regeneration following spinal cord injury in larval lamprey. Neuroscience 183, 265-277. doi: 10.1016/j.neuroscience.2011.03.024

Li, Y., Zhang, P., Choi, T. Y., Park, S. K., Park, H., Lee, E. J., et al. (2015). Splicingdependent trans-synaptic SALM3-LAR-RPTP interactions regulate excitatory synapse development and locomotion. Cell Rep. 12, 1618-1630. doi: 10.1016/j. celrep.2015.08.002

Luo, F., Tran, A. P., Xin, L., Sanapala, C., Lang, B. T., Silver, J., et al. (2018). Modulation of proteoglycan receptor PTPo enhances MMP-2 activity to promote recovery from multiple sclerosis. Nat. Commun. 9:4126. doi: 10.1038/s41467-018-06505-6

Lurie, D. I., Pijak, D. S., and Selzer, M. E. (1994). Structure of reticulospinal axon growth cones and their cellular environment during regeneration in the lamprey spinal cord. J. Comp. Neurol. 344, 559-580. doi: 10.1002/cne. 903440406

Martin, K. R., Xu, Y., Looyenga, B. D., Davis, R. J., Wu, C. L., Tremblay, M. L., et al. (2011). Identification of PTP $\sigma$ as an autophagic phosphatase. J. Cell Sci. 124, 812-819. doi: 10.1242/jcs.080341

McClellan, A. D. (1988). Brainstem command systems for locomotion in the lamprey: localization of descending pathways in the spinal cord. Brain Res. 457, 338-349. doi: 10.1016/0006-8993(88)90704-4

McKeon, R. J., Jurynec, M. J., and Buck, C. R. (1999). The chondroitin sulfate proteoglycans neurocan and phosphacan are expressed by reactive astrocytes in the chronic CNS glial scar. J. Neurosci. 19, 10778-10788. doi: 10.1523/JNEUROSCI.19-24-10778.1999

McLean, J., Batt, J., Doering, L. C., Rotin, D., and Bain, J. R. (2002). Enhanced rate of nerve regeneration and directional errors after sciatic nerve injury in receptor protein tyrosine phosphatase $\sigma$ knock-out mice. J. Neurosci. 22, 5481-5491. doi: 10.1523/JNEUROSCI.22-13-05481.2002

Ohtake, Y., Kong, W., Hussain, R., Horiuchi, M., Tremblay, M. L., Ganea, D., et al. (2017). Protein tyrosine phosphatase $\sigma$ regulates autoimmune encephalomyelitis development. Brain Behav. Immun. 65, 111-124. doi: 10.1016/j.bbi.2017.05.018

Ohtake, Y., Wong, D., Abdul-Muneer, P. M., Selzer, M. E., and Li, S. (2016). Two PTP receptors mediate CSPG inhibition by convergent and divergent signaling pathways in neurons. Sci. Rep. 6:37152. doi: 10.1038/srep37152

Rodemer, W., Zhang, G., Hu, J., and Selzer, M. (2015). "Expression of the CSPG receptor, LAR, after spinal cord transection in the lamprey," in 2015 Neuroscience Meeting Planner, ed. S. F. Neuroscience (Washington, DC).
Rovainen, C. M. (1967). Physiological and anatomical studies on large neurons of central nervous system of the sea lamprey (Petromyzon marinus). I. Müller and Mauthner cells. J. Neurophysiol. 30, 1000-1023. doi: 10.1152/jn.1967.30. 5.1000

Sapieha, P. S., Duplan, L., Uetani, N., Joly, S., Tremblay, M. L., Kennedy, T. E., et al. (2005). Receptor protein tyrosine phosphatase $\sigma$ inhibits axon regrowth in the adult injured CNS. Mol. Cell. Neurosci. 28, 625-635. doi: 10.1016/j.mcn.2004. 10.011

Selzer, M. E. (1978). Mechanisms of functional recovery and regeneration after spinal cord transection in larval sea lamprey. J. Physiol. 277, 395-408. doi: 10.1113/jphysiol.1978.sp012280

Shen, Y., Tenney, A. P., Busch, S. A., Horn, K. P., Cuascut, F. X., Liu, K., et al. (2009). PTP $\sigma$ is a receptor for chondroitin sulfate proteoglycan, an inhibitor of neural regeneration. Science 326, 592-596. doi: 10.1126/science.1178310

Shifman, M. I., Zhang, G., and Selzer, M. E. (2008). Delayed death of identified reticulospinal neurons after spinal cord injury in lampreys. J. Comp. Neurol. 510, 269-282. doi: 10.1002/cne.21789

Sobrido-Cameán, D., Robledo, D., Sánchez, L., Rodicio, M. C., and BarreiroIglesias, A. (2019). Serotonin inhibits axonal regeneration of identifiable descending neurons after a complete spinal cord injury in lampreys. Dis. Model. Mech. 12:dmm037085. doi: 10.1242/dmm.037085

Stichel, C. C., Niermann, H., D’Urso, D., Lausberg, F., Hermanns, S., and Muller, H. W. (1999). Basal membrane-depleted scar in lesioned CNS: characteristics and relationships with regenerating axons. Neuroscience 93, 321-333. doi: 10.1016/s0306-4522(99)00112-8

Südhof, T. C. (2018). Towards an understanding of synapse formation. Neuron 100, 276-293. doi: 10.1016/j.neuron.2018.09.040

Swain, G. P., Jacobs, A. J., Frei, E., and Selzer, M. E. (1994). A method for in situ hybridization in wholemounted lamprey brain: neurofilament expression in larvae and adults. Exp. Neurol. 126, 256-269. doi: 10.1006/exnr.1994.1063

Tadai, K., Shioiri, T., Tsuchimoto, J., Nagai, N., Watanabe, H., and Sugiura, N. (2018). Interaction of receptor type of protein tyrosine phosphatase $\sigma(\mathrm{RPTP} \sigma)$ with a glycosaminoglycan library. J. Biochem. 164, 41-51. doi: $10.1093 / \mathrm{jb} / \mathrm{mvy027}$

Takahashi, H., Arstikaitis, P., Prasad, T., Bartlett, T. E., Wang, Y. T., Murphy, T. H., et al. (2011). Postsynaptic TrkC and presynaptic PTP $\sigma$ function as a bidirectional excitatory synaptic organizing complex. Neuron 69, 287-303. doi: 10.1016/j.neuron.2010.12.024

Thon, N., Haas, C. A., Rauch, U., Merten, T., Fassler, R., Frotscher, M., et al. (2000). The chondroitin sulphate proteoglycan brevican is upregulated by astrocytes after entorhinal cortex lesions in adult rats. Eur. J. Neurosci. 12, 2547-2558. doi: 10.1046/j.1460-9568.2000.00109.x

Tran, A. P., Warren, P. M., and Silver, J. (2018). The biology of regeneration failure and success after spinal cord injury. Physiol. Rev. 98, 881-917. doi: 10.1152/physrev.00017.2017

Um, J. W., Kim, K. H., Park, B. S., Choi, Y., Kim, D., Kim, C. Y., et al. (2014). Structural basis for LAR-RPTP/Slitrk complex-mediated synaptic adhesion. Nat. Commun. 5:5423. doi: 10.1038/ncomms6423

Van der Zee, C. E., Man, T. Y., Van Lieshout, E. M., Van der Heijden, I., Van Bree, M., and Hendriks, W. J. (2003). Delayed peripheral nerve regeneration and central nervous system collateral sprouting in leucocyte common antigenrelated protein tyrosine phosphatase-deficient mice. Eur. J. Neurosci. 17, 991-1005. doi: 10.1046/j.1460-9568.2003.02516.x

Wanner, I. B., Anderson, M. A., Song, B., Levine, J., Fernandez, A., GrayThompson, Z., et al. (2013). Glial scar borders are formed by newly proliferated, elongated astrocytes that interact to corral inflammatory and fibrotic cells via STAT3-dependent mechanisms after spinal cord injury. J. Neurosci. 33, 12870-12886. doi: 10.1523/JNEUROSCI.2121-13.2013

Xiao, H., and $\mathrm{Wu}, \mathrm{R}$. (2017). Simultaneous quantitation of glycoprotein degradation and synthesis rates by integrating isotope labeling, chemical enrichment, and multiplexed proteomics. Anal. Chem. 89, 10361-10367. doi: 10.1021/acs.analchem.7b02241

Xie, Y., Yeo, T. T., Zhang, C., Yang, T., Tisi, M. A., Massa, S. M., et al. (2001). The leukocyte common antigen-related protein tyrosine phosphatase receptor regulates regenerative neurite outgrowth in vivo. J. Neurosci. 21, 5130-5138. doi: 10.1523/JNEUROSCI.21-14-05130.2001

Yi, J. H., Katagiri, Y., Yu, P., Lourie, J., Bangayan, N. J., Symes, A. J., et al. (2014). Receptor protein tyrosine phosphatase $\sigma$ binds to neurons in the 
adult mouse brain. Exp. Neurol. 255, 12-18. doi: 10.1016/j.expneurol.2014. 02.007

Yin, H. S., and Selzer, M. E. (1983). Axonal regeneration in lamprey spinal cord. J. Neurosci. 3, 1135-1144. doi: 10.1523/JNEUROSCI.03-06-01 135.1983

Yoshida, T., Shiroshima, T., Lee, S. J., Yasumura, M., Uemura, T., Chen, X., et al. (2012). Interleukin-1 receptor accessory protein organizes neuronal synaptogenesis as a cell adhesion molecule. J. Neurosci. 32, 2588-2600. doi: 10.1523/JNEUROSCI.4637-11.2012

Yoshida, T., Yasumura, M., Uemura, T., Lee, S. J., Ra, M., Taguchi, R., et al. (2011). IL-1 receptor accessory protein-like 1 associated with mental retardation and autism mediates synapse formation by trans-synaptic interaction with protein tyrosine phosphatase

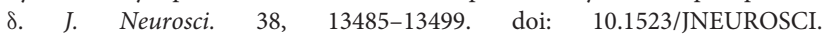
2136-11.2011

Zhang, G., Hu, J., Li, S., Huang, L., and Selzer, M. E. (2014). Selective expression of CSPG receptors PTP $\sigma$ and LAR in poorly regenerating reticulospinal neurons of lamprey. J. Comp. Neurol. 522, 2209-2229. doi: 10.1002/cne. 23529

Zhang, G., Jin, L. Q., Hu, J., Rodemer, W., and Selzer, M. E. (2015). Antisense morpholino oligonucleotides reduce neurofilament synthesis and inhibit axon regeneration in lamprey reticulospinal neurons. PLoS One 10:e137670. doi: 10.1371/journal.pone.0137670

Zhong, J., Lan, C., Zhang, C., Yang, Y., Chen, W. X., Zhang, K. Y., et al. (2019). Chondroitin sulfate proteoglycan represses neural stem/progenitor cells migration via PTP $/ \alpha$-actinin4 signaling pathway. J. Cell Biochem. 120, 11008-11021. doi: 10.1002/jcb.28379

Zuo, J., Neubauer, D., Dyess, K., Ferguson, T. A., and Muir, D. (1998). Degradation of chondroitin sulfate proteoglycan enhances the neurite-promoting potential of spinal cord tissue. Exp. Neurol. 154, 654-662. doi: 10.1006/exnr.1998.6951

Conflict of Interest: The authors declare that the research was conducted in the absence of any commercial or financial relationships that could be construed as a potential conflict of interest.

Copyright (c) 2020 Rodemer, Zhang, Sinitsa, Hu, Jin, Li and Selzer. This is an open-access article distributed under the terms of the Creative Commons Attribution License (CC BY). The use, distribution or reproduction in other forums is permitted, provided the original author(s) and the copyright owner(s) are credited and that the original publication in this journal is cited, in accordance with accepted academic practice. No use, distribution or reproduction is permitted which does not comply with these terms. 